\title{
O PAPEL DO DESIGN NO CONTEXTO DO ENSINO A DISTÂNCIA (EAD)
}

Gean Flávio de Araújo Lima, doutorando Universidade Federal de Santa Catarina

Eugenio Andrés Díaz Merino, PhD Universidade Federal de Santa Catarina eugenio.merino@ufsc.br

\author{
Giselle Schmidt Alves Díaz Merino, Dra \\ Universidade Federal de Santa Catarina \\ Universidade do Estado de Santa Catarina \\ gisellemerino@gmail.com \\ Ricardo Triska \\ Universidade Federal de Santa Catarina \\ ricardo.triska@gmail.com
}

Resumo: $\mathrm{O}$ artigo aqui apresentado percorreu pelo do universo do Ensino a Distância onde o design participa deste contexto que vai deste a elaboração de interfaces digitais para Ambientes Virtuais de Aprendizagem (AVAs) até o desenvolvimento do material instrucional de onde o design pode ser peça essencial no processo de ensino e aprendizagem. $O$ discurso principal abordado é de como que o design tem contribuído no contexto de $\mathrm{EaD}$ e de que forma ele interfere no processo onde o aluno está disposto a aprender em um cenário onde há o uso de um ambiente virtual em plataforma pré configurada, a ausência total ou parcial do professor, a utilização de materiais de suporte no AVA com características particulares ao processo de ensino desta modalidade. A finalidade desta pesquisa foi de mapear o contexto que envolve o design no processo de ensino a distância para estabelecimento do aprendizado. Para efetivar o que se propões foi feita uma Revisão Sistemática com intenção de identificar onde o design tem interferido no contexto educacional, no âmbito dos projetos de AVAs e no design de serviços que beneficiam o contexto educacional. Foi possível assim identificar a forma como o design tem sido usado/aproveitado no contexto do ensino a se percebeu em quais dimensões do contexto do $\mathrm{EaD}$ o design interfere (ou podem interferir) no processo de forma direta ou indireta, e também que foi possível identificar a relevância do design no contexto do ensino a distância.

Palavras-chave: Design, Ensino a Distância, Gestão de design

\begin{abstract}
The paper presented here come by the Teaching universe Distance where design participates in this context that goes from the development of digital interfaces for Virtual Learning Environments (VLES) to the development of instructional material from which the design can be essential part in the process teaching and learning. The addressed keynote address is how the design has contributed in the context of distance education and how it interferes in the process where the student is willing to learn in a setting where there is the use of a virtual environment in pre
\end{abstract}


configured platform, the complete absence or part of the teacher, the use of support materials with particular characteristics VLE in the teaching process of this embodiment. The purpose of this study was to map the context in which the design in distance teaching process to the learning establishment. To accomplish what you propose was made a systematic review intended to identify where design has interfered in the educational context, within VLEs projects and design services that benefit the educational context. It was thus possible to identify how the design has been used / leveraged in the context of teaching to be realized in which distance education context dimensions design interferes (or may affect) in the process of directly or indirectly, and also that it was possible to identify the relevance of design in the context of distance education.

Keywords: Design, Distance Learning, Design management

\section{INTRODUÇÃO}

Os computados já não são usados apenas como um local de uso de ferramentas para facilitar a vida, mas também vem possibilitando a imersão em um universo variado de informações boas e ruins. E segundo Lévy (2001), considerar que o computador serve somente como um instrumento para produzir textos, sons ou imagens sobre suporte fixo é negar os novos gêneros ligados à interatividade.

Então não se pode negar que o comportamento das pessoas tem se modificado não somente por conta dos computadores pessoais, mas também pelos smartphones e tablets cada vez mais acessíveis. Como essa mudança afeta os indivíduos e os sistemas, o processo de ensino e aprendizado não poderia ficar alheio a este novo cenário.

Hoje o ensino online tem sido uma alternativa para superar questões de distância e de tempo, pois a facilidade com que o ensino tem se tornado acessível permite que as pessoas consigam adequar a busca pelo aprendizado em seu cotidiano.

Para Moran (2003, p.14),

A educação online pode ser interpretada como um conjunto de ações de ensino-aprendizagem desenvolvidas por meios telemáticos, Internet, videoconferência e teleconferência, e que acontece dos níveis mais elementares aos mais especializados nos sistemas formais e informais de ensino. "Abrange desde cursos totalmente virtuais, sem contato físico - passando por percursos semipresenciais - até cursos presenciais com atividades complementares fora de sala de aula, pela internet."

Esse acesso fácil a educação tem sido possível através das plataformas desenvolvidas parar esse fim, tais como TelEduc, AulaNet, Amadeus, Eureka, Moodle, entre outras tem ajudado no processo de gerenciamento e de acesso ao conteúdo de aprendizado.

Diante dessas tecnologias disponíveis Moran (2003) faz distinção entre o conceito de Educação a Distância e educação online, para ele o primeiro compreende um conceito mais amplo que pode incluir a formação por meio de materiais impressos, 
sem a utilização de suportes eletrônicos de telecomunicações e de rede, sendo o ensino online, porém, seria mais uma das múltiplas estratégias da formação a distância.

Para Gomes (2008), a quarta geração de EaD se designa como aprendizagem em rede. Os conteúdos são representados por suportes multimídias que proporcionam a interação dos participantes com as mídias digitais da terceira geração, mas usufrui das potencialidades da comunicação sob a rede de computadores, Internet, que promove a comunicação assíncrona e síncrona entre professores e alunos e estes entre si.

As plataformas digitais de EaD, as AVAs, podem, de certa forma, facilitar o acesso ao conteúdo e também ajudar no gerenciamento destes assim como na administração dos procedimentos didáticos. Os conteúdos disponibilizados nas AVAs servem para dar suporte ao aprendizado e a interação do usuário/aluno com o ambiente virtual permite que ele gerencie seu processo de aprendizagem.

Todo o universo do EaD requer interações de diversos níveis e por mídias diversificadas e isso tudo precisa de uma boa interface, seja ela física ou virtual. É nesse contexto que o design pode (e deve) atuar, mas como o EaD vem absorvendo o design? É baseado nesse discurso que aqui se pretende saber qual é a relação do design com o contexto do ensino e aprendizagem no sistema que configura o Ensino a Distância.

\section{DESENVOLVIMENTO}

Ao mesmo tempo em que os recursos tecnológico estão sendo usados como forma de promover o processo de EaD, não se pode negligenciar os aspectos relacionados a interação dos usuários com esses recursos, sejam eles digitais/virtuais ou físicos/táteis. Os anseios e as frustrações dos indivíduos que interagem com sistemas físicos e digitais vêm sendo considerados como elementos determinantes para o sucesso da interação.

Pensando na complexidade que é o projeto de uma interface, seja pra qual finalidade for, onde aspectos como arquitetura da informação, design de interação, experiência do usuário, entre outros devem ser verificados, considerando a complexidade que é o processo de educação, surgiu o questionamento sobre a relação entre a interface e o processo de aprendizagem, pois é possível que a forma como o design das interfaces dos AVAs esteja influenciando o processo de aprendizagem. No universo físico estão os materiais impressos que ainda constituem o aparato usado para suporte do ensino, que também podem ser disponibilizados de forma digital ficando a critério de o aluno imprimir, ou não. Estes também possuem interação com o usuário e deve ser desenvolvido dentro dos pressupostos da educação e da ergonomia instrucional, do design instrucional que, igualmente complexo, deve permitir que o conteúdo seja acessado de forma eficiente e eficaz.

Dessa forma a pesquisa aqui proposta buscou estabelecer uma relação entre design e o ensino e aprendizado e identificar se a abrangência desta relação vai além do que diz respeito à aplicação de técnicas de projetação identificando de que forma o design tem sido usado/aproveitado e que se perceba quais dimensões do contexto do EaD interferem (ou podem interferir) de forma direta ou indireta no papel do design 
no processo. Além disso, buscou-se também identificar a relevância do design (como ferramenta e como gestão) no contexto do ensino a distância.

Para tanto o método utilizado para efetivar o que se propões é a Revisão Sistemática nas bases cientificas mais populares em um período mais recente (sem desconsiderar os clássicos) para identificar onde o design tem interferido no contexto educacional, no âmbito dos projetos de AVAs e no design de serviços que beneficiam o contexto educacional.

\subsection{O Ensino a Distância, aprendizagem à distância e AVAs}

A possibilidade de adquirir conhecimento através de um ambiente digital e a distância vem transformando o acesso à educação. Assmann (2005, apud Gonçalves, 2011) diz que as transformações sofridas na educação com o aparecimento das redes digitais pressupõem novas formas de raciocinar os processos de formação, pois estabelecem um conjunto de novos significados para as situações de ensino e aprendizagem. Essa novas formas são destacadas a seguir:

- Transformação no pensamento linear para o hipertextual;

- Ambiente de aprendizagem mais próximo da natureza viva e interdisciplinar do processo de construção do conhecimento e da interatividade dos processos cognitivos;

- Novo sentido de aprender, agora associado a aprendizagem ao longo da vida;

- Desenvolvimento da capacidade de colocar e resolver problemas;

- Exercitar a curiosidade, explorar a dúvida;

- Desenvolvimento do pensamento complexo, capaz de estabelecer elos para o contextualizar e globalizar os saberes. (p. 61-63).

Rosenberg (2007) estima um e-learning menos associado a um curso e mais voltado ao conhecimento, e para isso considera o uso da web 2.0 como fundamental. Ele destaca a importância das novas ferramentas e tecnologias, assim como as comunidades de prática, wikis, blogs, podcasts (and videocasts), mensagens instantâneas, e redes de relacionamento, que dão aos profissionais do ensino não somente novas oportunidades de criar e distribuir conteúdo, mas novas formas de criar interação entre os estudantes.

Os Ambientes Virtuais de Aprendizagem (AVA) aparecem como instrumento de mediação entre alunos e educadores, possibilitam que o conteúdo das aulas seja disponibilizados aos usuários/alunos e que haja interação e participação destes através de vários recursos e ferramentas que podem variar de acordo com a necessidade.

Os AVAs vêm crescendo e apresentando um elevado potencial de aplicação. Eles são caracterizados como interativos, onde os usuários dispersos geograficamente têm como objetivos a cooperação e o compartilhamento dos recursos computacionais em tempo real usando o suporte de rede de computadores para melhorar o desempenho coletivo por meio da troca de informações. (SINGHAL, ZYDA, 1999 apud MESQUITA, 2013). 
Ambiente virtuais de aprendizagem não atendem somente as atividades de ensino a distância, mas também auxiliam nas semipresenciais e presenciais complementando o processo de aprendizado.

O que se percebe é uma crescente prática da utilização de recursos tecnológicos para a comunicação dos conteúdos didáticos e troca de conhecimento, e sobre isso destacasse a preocupação que se deve ter com o processo de ensino e aprendizagem. ALONSO (2000) comenta que,

É importante perceber que o uso das tecnologias da comunicação não muda, em princípio, as questões inerentes a qualquer projeto educativo. Há sempre que responder: para quem, para quê e como o projeto será desenvolvido. $O$ processo de ensino-aprendizagem deve contextualizar a teoria e aproximá-la da realidade acadêmica. Quando se desenvolve um ambiente de aprendizagem, faz-se uma opção teórico-metodológica.

A partir deste discurso aonde as tecnologias da comunicação vem sendo usadas como mediadoras do conteúdo didático para o aluno, tem configurado uma revolução na forma de adquirir aprendizagem, e dessa forma o aluno precisa acompanhar tais mudanças, como será visto a seguir.

\subsection{Características dos alunos de EaD}

O aprendizado é efetivo a partir do momento que o aluno emprega esforço e motivação par tal, e para isso é necessário estar bem claro o que se deseja aprender e assim tomar posse das novas ideias na mente em consonância com as já existentes, construindo outros saberes.

No Ensino a Distância o professor tem um papel diferente do ensino presencial. Valente (2003, apud CAPELLINI et al 2011) ressalta que, nesse contexto, o professor deixa de ser o "entregador" de informação para exercer o papel de facilitador do processo de aprendizagem. $O$ aluno deixa de ser passivo, receptáculo das informações, para ser ativo aprendiz, construtor do seu conhecimento.

Segundo Capellini et al (2011), para ser aluno de cursos de Educação a Distância, é necessário que o pretendente tenha: condições de acesso ao computador, compatíveis às necessidades do curso; autonomia, para questionar e buscar respostas para seus questionamentos, isto é, exercitar o aprender sozinho, persistência e interesse pelos estudos. $O$ aluno gerenciando suas atividades de ensino juntamente as do dia-a-dia, acaba sendo um exercício constante de administração do tempo e, muitas vezes foge do controle. Isso pode gerar frustrações quando se pretende estabelecer uma rotina de estudos. Para Niskier (1999, apud CAPELLINI et al 2011),

O aluno da Educação a Distância precisa ter postura própria e atender a demandas diferenciadas, pois ele não deve atuar como receptor passivo de mensagens, mas sim como aluno autônomo, que se desenvolve a partir de seu ritmo. Para isso, necessita de muito mais atenção por parte do tutor, estímulo e incentivos mediante $e$ mail, chat, enfim, qualquer um dos recursos da tecnologia que possibilite a comunicação com o seu formador. Além disso, a motivação também parte das orientações sobre a forma de uso do 
material, que devem ser claras e precisas, daí a ênfase no papel do professor quanto à preparação do mesmo.

É neste ponto que se deve observar o conceito de instrucional, onde a preocupação com a forma que o conteúdo será apresentado para o aluno toma características próprias inerentes aos princípios pedagógicos. Segundo Dick \& Carey (1996), instrução é um processo sistemático, no qual cada componente (isto é, professores, estudantes, materiais e ambiente de aprendizagem) é crucial para o sucesso da aprendizagem.

$\mathrm{O}$ designer instrucional tem papel fundamental neste contexto do EaD, pois a partir dele que o conhecimento será absorvido de forma clara e objetiva. A respeito disso será abordado a seguir com maior profundidade as formas como o designer pode, e deve contribuir para o EaD.

\subsection{O design e o EaD: interferências e contribuições}

Há muitos anos o conceito de design tem sido discutido e, desde o estabelecimento do design como formação profissional, muito tem sido ditos sobre o oficio. O conceito tem sido moldado a partir das atribuições que o designer tem tomando para si à medida que o mercado demanda, mas o que permanece quase que intactas são as funções do design. LANGENBACH (2008) explica a seguir as funções do design:

A função prática, ou a funcionalidade de determinado artefato é a parte técnica de como a utilização desse artefato pelo homem, pode ser feito da melhor maneira possível. É relativa a usabilidade e performance."

A função estética está intimamente relacionada com a questão simbólica, dialoga com o gosto e o desejo do ser humano pelo belo. Não é limitada à esfera visual, mas é ligada com as ideias e o conteúdo ligado a sua imagem, é uma construção subjetiva.

A função simbólica é a que tenta compreender o imaginário e a subjetividade do homem para qual se está projetando. O simbólico está intimamente ligado ao local e à cultura daquela realidade.

De acordo com o International Council of Societies of Industrial Design (ICSID, 2016): Design é uma atividade criativa com o propósito de estabelecer as qualidades multifacetadas de objetos, processos, serviços e seus sistemas, compreendendo todo seu ciclo de vida. Portanto, design é o fator central da humanização inovadora de tecnologias e o fator crucial para o intercâmbio econômico e cultural. O design procura identificar e avaliar relações estruturais, organizacionais, funcionais, expressivas e econômicas, visando:

- Ampliar a sustentabilidade global e a proteção ambiental (ética global);

- Oferecer benefícios e liberdade para a comunidade humana como um todo, usuários finais individuais e coletivos, protagonistas da indústria e comércio (ética social);

- Apoiar a diversidade cultural, apesar da globalização do mundo (ética cultural);

- Dar aos produtos, serviços e sistemas, formas que expressem (semiologia) e sejam coerentes com (estética) sua própria complexidade. 
Baseado na definição do ICSID ${ }^{1}$, Langenbach (2008) completa que,

O design diz respeito a produtos, serviços e sistemas concebidos a partir de ferramentas, organizações e lógicas introduzidas pela industrialização - não apenas quando produzidos por meio de processos seriados. $\mathrm{O}$ adjetivo "industrial" associado ao design deve relacionar-se ao termo indústria, ou no seu sentido de setor produtivo, ou em seu sentido mais antigo de "atividade engenhosa, habilidosa". Assim, o design é uma atividade que envolve um amplo espectro de profissões nas quais produtos, serviços, gráfica, interiores e arquitetura, todos participam. Juntas, essas atividades deveriam ampliar ainda mais - de forma integrada com outras profissões relacionadas - o valor da vida. Dessa forma o termo designer se refere a um indivíduo que pratica uma profissão intelectual, e não simplesmente oferece um negócio ou presta um serviço para as empresas.

Considerando as funções do design, as definições vistas anteriormente e a capacidade que o designer tem se envolver no contexto de forma sistemática podendo contribuir com as questões tangíveis e intangíveis no processo de desenvolvimento projetual a fim de atender as necessidades inerentes ao problema, constata-se que o designer se instala em uma posição que transita por dois universos distintos e correlacionados no contexto do EaD. No esquema da figura 01 a seguir é possível perceber este universo.

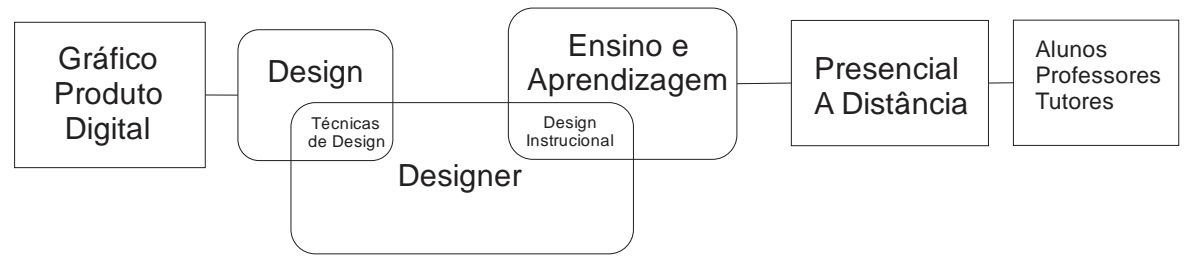

Figura 1 - Contexto da atuação do designer no universo do EaD.

Fonte: "Elaborado pelo autor, com base na pesquisa realizada".

A partir do esquema apresentado se pode observar que o design tem se transformando a medida que a sociedade evolui e se transforma e sobre isso Langenbach (2008) hoje se mostra necessário repensar esse termo, suas definições e qual o papel que o designer pode ter na sociedade atual na busca de uma melhor qualidade de vida e de um sistema sustentável. O autor completa que

Deve-se iniciar esse processo com um entendimento contextual de nossa sociedade, entendendo, primeiramente, a mudança da sociedade, na qual a produção industrial (produção de tangíveis) vem perdendo importância para as produções de intangíveis, percebendo então que essas estruturas de produção de intangíveis, incluindo-se a produção de serviços, têm se tornado o principal fator de desenvolvimento no mundo atual.

\footnotetext{
${ }^{1}$ International Council of Societies of Industrial Design. http://www.icsid.org. Acesso em maio de 2016.
} 
Observando novamente a figura 01 destaca-se que o designer, no contexto da EaD tem participação naquilo que é interface entre o aluno e o material didático do curso - o design instrucional, que também está incluso a interface do Ambiente Virtual de Aprendizagem, e Morer (2007) defende que, na verdade, o e-learning bem sucedido reside no equilíbrio do incremento à qualidade na educação e no design instrucional: ou seja, a direção da educação versus a direção da tecnologia. Não é possível considerar um e desdenhar o outro.

Então é importante verificar que o designer se torna um agente de mediação entre o educador e o aluno, pois precisa transformar o material didático para o EaD em uma forma de promover uma experiência mais objetiva no processo de aprendizagem, pois segundo Filatro ( 2004) o Design Instrucional é uma ação intencional e sistemática de ensino, que envolve o planejamento, o desenvolvimento e a utilização de métodos, técnicas, atividades, materiais, eventos e produtos educacionais em situações didáticas específicas, a fim de facilitar a aprendizagem humana a partir dos princípios de aprendizagem e instrução conhecidos.

Segundo a Classificação Brasileira de Ocupações- $\mathrm{CBO}^{2}$, designer instrucional é sinônimo de designer educacional, registrado sob o código 2394-35 e descrito da seguinte forma:

Implementam, avaliam, coordenam e planejam o desenvolvimento de projetos pedagógicos/instrucionais nas modalidades de ensino presencial e/ou a distância, aplicando metodologias e técnicas para facilitar o processo de ensino e aprendizagem. Atuam em cursos acadêmicos e/ou corporativos em todos os níveis de ensino para atender as necessidades dos alunos, acompanhando e avaliando os processos educacionais. Viabilizam o trabalho coletivo, criando e organizando mecanismos de participação em programas e projetos educacionais, facilitando $o$ processo comunicativo entre a comunidade escolar e as associações a ela vinculadas.

Sobre sua Formação e Experiência, $\mathrm{O}^{\mathrm{CBO}^{1}}$ cita que o exercício dessas ocupações requer curso superior na área de educação ou áreas correlatas. $O$ desempenho pleno das atividades ocorre após três ou quatro anos de exercício profissional. Dessa forma verifica-se que o designer instrucional não é necessariamente um designer com formação superior em design ou desenho industrial, mas sim um profissional que tenha relação com área da educação, podendo pertencer a ocupações Relacionadas, como Coordenador pedagógico, Orientador educacional, Pedagogo, Professor de técnicas e recursos audiovisuais, Psicopedagogo ou Supervisor de ensino (CBO).

Nota-se que a palavra "designer" quando empregado no termo Designer Instrucional (ou Designer educacional, ou Desenhista instrucional, Projetista instrucional - sinônimos, segundo a $\mathrm{CBO}$ ) refere-se a característica projetual da atividade de design instrucional como pode-se perceber pela descrição da $\mathrm{CBO}$, e não ao profissional que a executa, que no caso não é um designer de formação. Então o design que está sendo praticado no contexto do EaD tem tido a participação dos designers de formação?

\footnotetext{
${ }^{2}$ http://www.ocupacoes.com.br/cbo-mte/239435-designer-educacional, acesso em maio de 2016.
} 
Segundo Silva e Castro (2009), ao produzir-se material didático é imprescindível considerar-se os objetivos do material, que Ausubel (2000) cita que um material didático só pode ser considerado de qualidade e relevante quando este se encontra organizado e programado. Segundo Ministério da Educação - MEC,

Todos estes objetivos devem estar nitidamente especificados no projeto pedagógico do curso que deve também explicitar a equipe multidisciplinar envolvida no processo, citando desde o professor e autor responsável por cada disciplina até os demais profissionais como, por exemplo, webdesigners, designers gráficos, designers instrucionais, revisores, equipe de vídeo, etc.

Analisando o que MEC (2007) orienta é salutar que no projeto de um curso haja uma equipe multidisciplinar onde estariam incluídos os designers para atuarem tanto no material gráfico como no material digital dos AVAs.

Para Silva e Castro (2009), pode-se destacar 5 atores relevantes ao processo de produção do material educacional, são eles: professores, docentes, renomados e experientes, responsáveis pela produção do conteúdo pela produção do conteúdo e complementação das informações, quando sugeridas pelo Designer Instrucional e também pela comissão editorial; designer Instrucional, responsável pela adaptação metodológica do material e análise das informações do texto além de contribui para um material mais atrativo com links e saiba mais, por exemplo; revisor de textos, profissional que executa a correção ortográfica e sintaxe do texto; diagramador, responsável pelo formato gráfico do texto; e, comissão editorial, equipe responsável por acompanhar toda produção do material, verificando se o mesmo está de acordo com a ementa da disciplina e a proposta pedagógica do curso.

Até aqui nota-se o caráter operacional atribuído ao designer no que diz respeito a sua participação no contexto do $\mathrm{EaD}$ com interferências no desenvolvimento do material didático e na elaboração da interface dos Ambientes Virtuais de Aprendizagem, como orienta o MEC e comenta Silva e Castro (2009). O que mais o designer pode oferecer ao Ensino a Distância além de ser meramente um fazedor daquilo que os designers instrucionais dizem que deve ser feito? A seguir discute-se esta possibilidade inovadora de contribuição do designer.

\subsection{Perspectivas para o design no EaD}

Considerando que a aprendizagem em e-learning deve ser contextualizada, significativa e colaborativa, quando "na rede flutuam instrumentos privilegiados de inteligência coletiva, capazes de gradual e processualmente fomentar uma ética por interações, assentada em princípios de diálogo, de cooperação, de negociação e participação" (MORAES, 2001 apud GABARDO, 2010), estaria a plataforma construída de forma a proporcionar tudo isso? E mais: estão as plataformas adequadamente aptas a tornar o estudo mais fácil e melhor; oferecem ferramentas necessárias a um desenvolvimento autônomo, a fim de que o estudante possa aperceber-se de que desenvolve conhecimento por si, gerando mais comprometimento? (GABARDO, 2010)

Langenbach (2008) lembra que o designer tem um papel fundamental na relação entre sociedade e tecnologia, já que faz a ponte entre as duas áreas, humanizando a tecnologia para que esteja a serviço do homem. Porém, não só na 
parte prática e utilitarista, como a visão preponderante e superficial da sociedade atual nos indica, mas olhando também a função estética e principalmente a função simbólica das tecnologias na sociedade. Esse olhar é extremamente importante quando se trata dos serviços, e significa também, olhar e entender as culturas dos locais para os quais se projeta.

Diante destes aspectos apresentados sobre o e-learning e o papel do designer na sociedade atual, apresenta-se na figura 02 a seguir uma perspectiva de reposicionamento na atuação do designer inserindo a prática da gestão nas questões estratégicas e nas tomadas de decisão, principalmente quando a gestão de design tem potencial para oferecer mais eficiência e eficácia e, sobretudo, inovação nos processos. Dentro do processo de gestão autores com Tim Brown (2010) sugerem uma sequência ordenada de etapas - as "três etapas de inovação": inspiração onde insights de todos os tipos são coletados, ideação onde os insights são traduzidos em ideias e implementação onde as melhores ideias são desenvolvidas em plano de ação concreto. Então estas etapas também são apresentadas como norteadora para a atuação do designer dentro desta perspectiva apresentada.

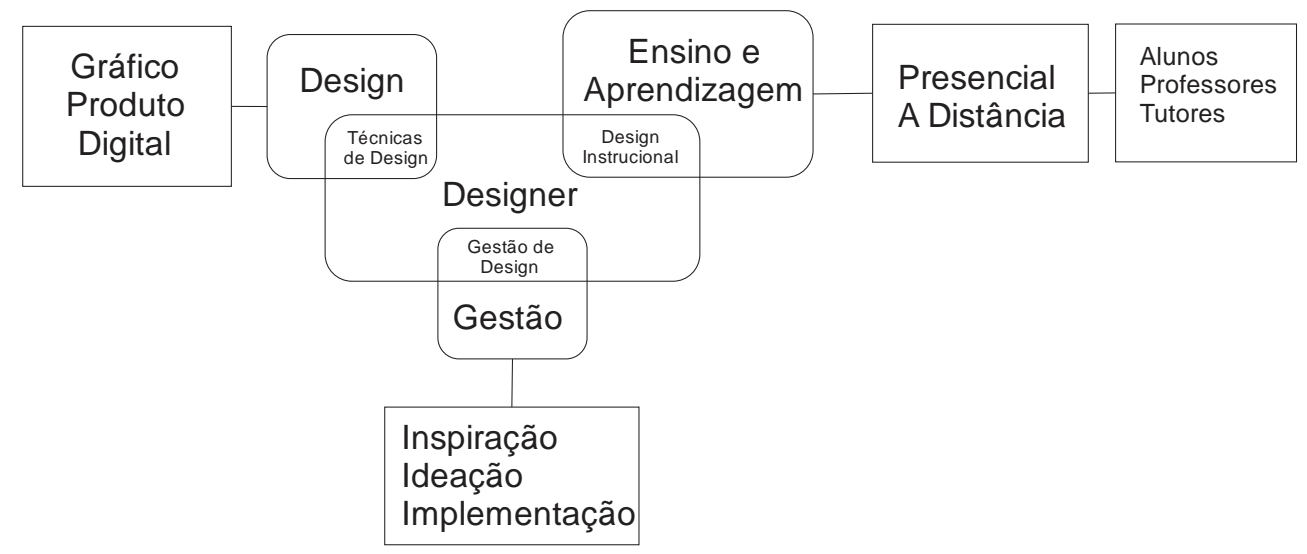

Figura 2 - Perspectiva para a atuação do designer no universo do EaD.

Fonte: "Elaborado pelo autor, com base na pesquisa realizada".

Segundo Martins e Merino (2011), a gestão contribui para com o design permitindo-lhe aplicar ferramentas de decisões, diagnósticos, articulação e coordenação para a eficácia dos projetos, inclusive de diversos projetos interrelacionados segundo o direcionamento dado pela gestão da organização, potencializando a percepção de suas qualidades perante seu publico interno e externo.

Desta forma, ao se inserir a gestão na prática das atividades do designer ele assume funções que vão além daquelas que foram originalmente atribuídas a ele, e essa atividade de gestão vem sido comumente adotada pelos designers onde a realização dos projetos tem sido transformada pela participação de uma equipe interdisciplinar e também pela participação dos usuários, utilizando a Experiência do Usuário como elemento facilitador de identificação das informações mais próximas do que realmente o ele precisa.

Segundo Roda e Krucken (2004)

A gestão de design apresenta uma visão sistêmica e integrada da atuação do designer nas organizações, que é fundamental para a 
coordenação das atividades e das visões estratégicas que mantêm a organização a curtos, médios e longos prazos. Desta forma desempenha um papel na "criação de sinergia organizacional".

Assim o designer, munido de princípios metodológicos e de ferramentas de gestão, tem capacidade de promover transformações no processo de elaboração de um curso de EaD visto que o perfil deste profissional no mercado tem gerado resultados inovadores, pois a atividade de design pode contribuir para com a orientação empresarial através de seu caráter projetual, no que diz respeito ao arranjo de fatores que determinem um trajeto inovador rumo a um objetivo, e as metodologias e práticas de design podem contribuir para a etapa de "planejar" da gestão, colocando a empresa como um macroprojeto de inovação contínua, a partir da inovação setorial (PALMIERI; FIGUEIREDO, 2012).

\section{CONCLUSÃO}

Considerando o objetivo proposto neste artigo, verifica-se que foi atendida a proposta de mapear o papel do design no contexto de EaD, pois a sistematização da pesquisa bibliográfica foi primordial para identificar o cenário em que o uso do design é essencialmente como ferramenta de execução daquilo que é determinado pela equipe multidisciplinar comandada pelo designer instrucional. Não há uma participação do designer nas fases estratégicas onde as decisões são tomadas a respeito do que se deve apresentar aos alunos dentro dos preceitos do bom design instrucional.

Os discursos dos autores que tratam sobre o processo de gerenciamento da educação a distância e a elaboração do material instrucional tem muito das características daquilo que é denominado a gestão de design, principalmente quando se diz que e-learning requer romper, derrubar as barreiras, e também quando diz que envolve abrir um convite a todos os grupos em direção ao diálogo, o que condiz com o discurso de Palmieri e Figueiredo (2012) onde dizem que ao assumir o método e/ou processo de design, a organização fortalece o caráter de planejamento da gestão, contribuindo para um ambiente favorável à inovação, e por consequência, à melhoria continua.

A característica de em criar a sinergia organizacional do designer que prática a gestão de design vem a contribuir com o que o todos os atores envolvidos no processo de EaD, desde sua concepção até sua aplicação, sejam envolvidos no sistema. Essa capacidade de explorar o potencial criativo das pessoas que fazem parte da organização permite que a visão inovadora seja praticada com mais frequência e que soluções surjam com maior qualidade e intensidade.

Com a mudança na sociedade que passou a ter a informação disponível e imediata fez com que o papel do designer deixasse de ser o de projetar baseado em objetivos para encontrar soluções ao aplicar a técnica por procedimentos metodológicos, passando a participar da tomada de decisões em todas as instâncias da organização utilizando as ferramentas de gestão e adotando uma postura menos técnica e mais estratégica, deixando de ser somente operacional e passando a ser também tático e estratégico. 
A perspectiva do design mostrada neste artigo possibilita uma grande contribuição para o EaD, pois o designer, ao pôr em prática a gestão, se envolver com as equipes multidisciplinares, com os profissionais de educação e os alunos, para discutir sobre questões que envolvem o processo de ensino e aprendizagem de acordo com os projetos de cada curso. Os novos caminhos para o EaD e pro design tem potencial para inovar neste segmento, e há um vasto campo a ser pesquisado.

\section{REFERÊNCIAS}

ASSMANN, Hugo (Org.). Redes digitais e metamorfose do aprender. Petrópolis: Vozes, 2005.

AUSUBEL, David P. The Acquisition and Retention of Knowledge: A Cognitive View. Holanda: Kluwer Academic Publishers, 2000.

BROWN, T. Design thinking: uma metodologia poderosa para decretar o fim das velhas ideias. Rio de Janeiro: Elsevier, 2010.

CAPELLINI, Vera Lúcia Messias Fialho et al. Perfil e avaliação dos participantes de um curso de formação continuada em práticas educacionais inclusivas na modalidade a distância. Práxis Educativa, Ponta Grossa - Pr, v. 6, n. 1, p.79-89, jun. 2011. Semestral. Disponível em: <http://www.periodicos.uepg.br>. Acesso em: 11 maio 2016.

DICK, Walter. CAREY, Lou..The Systematic Design of Instruction. Fourth Edition. Harper Collins, 1996. College Publishers, New York USA.

FILATRO, 2004, p. 65, Design instrucional contextualizado: educação e tecnologia. São GONÇALVES, Carolina Brandão. Educação a Distância: a aprender online. Rev. ARETÉ Revista Amazônica de Ensino de Ciências. Manaus. v. 4. n. 6. p.24-34. 2011.

GABARDO, Patrícia; QUEVEDO, Silvia R. P. de; ULBRICHT, Vânia Ribas. Estudo comparativo das plataformas de ensino-aprendizagem. Enc. Bibli: R. Eletr. Bibliotecon. Ci. Inf., [s.I.], p.65-84, 2010. Universidade Federal de Santa Catarina (UFSC). http://dx.doi.org/10.5007/1518-2924.2010v15nesp2p65.

GOMES, M. J. Gerações de inovação no ensino a distância. Universidade do Minho, 2003.:. Disponível em: <http://repositorium.sdum.uminho.pt/bitstream/

LANGENBACH, Marcos Lins. Além do apenas funcional: Inovação social e design de serviços na realidade brasileira. 2008. 123 f. Dissertação (Mestrado) - Curso de Engenharia de Produção, Coppe, Ufrj, Rio de Janeiro - Rj, 2008. Disponível em: <www.ivt-rj.net/ivt/bibli/marcos_lins_langenbach.pdf>. Acesso em: 25 abr. 2016.

LÉVY, Pierre. A Conexão Planetária: o mercado, o ciberespaço, a consciência. São Paulo: Editora 34, 2001.

MARTINS, Rosane Fonseca de Freitas, MERINO, Eugenio A. D. Gestão de Design como Estratégia Organizacional. 2a. ed. Londrina: EDUEL, 2011.

MESQUITA, F. G. Protocolo para avaliação do uso de Ambientes Virtuais de Aprendizagem em instituições de ensino superior. 2011. $110 \mathrm{f}$. Dissertação (Mestrado) - Faculdade de Economia, Administração e Contabilidade de Ribeirão Preto, Universidade de São Paulo, Ribeirão Preto, 2011. 
Ministério da Educação, BRASIL. Referenciais de qualidade para Educação superior a distância. Secretaria de Educação a Distância, Brasília: [s.n.]. 2007.

MORAN, J. M. Contribuições para uma pedagogia da educação online. In M. Silva (Org.), Educação Online. Brasil, São Paulo: Loyola. 2003.

PALMIERI, Alberto Ribeiro; FIGUEIREDO, Luiz Fernando Gonçalves de. Função própria e pertinente da gestão de design. DApesquisa, Florianópolis, v. 1, n. 9, p.498-509, julho 2012.

SILVA, M. Criar e professorar um curso online: relato de experiência. In M. Silva (Org.), Educação online. Brasil, São Paulo: Loyola. pp.155-158, 2003. 